\title{
Thermo-mechanical properties of fused borosilicate syntactic foams
}

\author{
Z. Salleh ${ }^{1}$, M. M. Islam ${ }^{2}$, J. A. Epaarachchi ${ }^{2}$ and M. T. I. Khan ${ }^{3}$ \\ ${ }^{1}$ Universiti Kuala Lumpur, Technical Foundation Section, Malaysian Institute of Marine \\ Engineering Technology, Dataran Industri Teknologi Kejuruteraan Marin, Bandar \\ Teknologi Maritim, Jalan Pantai Remis, 32200 Lumut Perak, Malaysia, \\ Phone: +605-690-9000; Fax: +605-690-9091 \\ *Email: zulzamri@unikl.edu.my \\ ${ }^{2}$ Centre for Future Materials (CFM) and School of Mechanical and Electrical Engineering, \\ Faculty of Health, Engineering and Sciences, University of Southern Queensland, \\ Toowoomba, Queensland 4350, Australia. \\ ${ }^{3}$ Department of Advanced Technology Fusion, Faculty of Science and Engineering, \\ Saga University, Saga 840-8502, JAPAN
}

\begin{abstract}
The properties regarding thermal stability of syntactic foam such as coefficient thermal expansion, $\alpha$ (CTE) had been investigated in this paper. Determination of CTE in composite materials is commonly used for application in heat exchange transformation. The CTE comparison using kinetic theory model has not really been investigated yet for composite materials. The syntactic foam prepared by mixing fused borosilicate or glass microballoon with matrix resin were considered in this study. The different weight percentage of glass microballoon varied from $2 \mathrm{wt} . \%$ to $10 \mathrm{wt} . \%$ were analysed using thermo-mechanical analyser (TMA). The results showed that CTE value became up to 53-63\% lower than the pure resin after mixing with different weight percentages (2wt.\%-10wt.\%) of glass microballoon. Experimental results showed that the CTE decreases when glass microballoons are added into the composites measured at different temperatures ranging from $30^{\circ} \mathrm{C}$ to $70^{\circ} \mathrm{C}$. The $\mathrm{CTE}$ from the experimental results were also compared with Turner's modification model for composites for its suitability for thermal expansion of syntactic foams. The results indicate that Turner's modification model exhibits a close correlation with the reduction up to $80 \%$ of CTE based on experiment.
\end{abstract}

Keywords: Coefficient; thermomechanical; composites; syntactic foam; porosity.

\section{INTRODUCTION}

Fused borosilicate or glass microballoon particles when mixed with a resin matrix can be considered as a closed cell foam or syntactic foam. Previously numerous works that have been carried out on particular syntactic foam characterized the mechanical properties, and also physical properties such as density, volume fraction, wall thickness and porosity [1-4]. Physical properties such as density syntactic foam, including a radial wall thickness ratio, porosity and voids are most likely to be very effective in tailoring mechanical properties of 
syntactic foam [5]. This type of lightweight materials is useful for aerospace [6], marine, thermal insulation and packaging [7] because of their good mechanical properties for the environment. It will lead to a concern subject to high temperatures and thus it is important to determine the coefficient of thermal expansion, $\alpha$ (CTE) [8]. Determination of CTE between the insulation and the substrate is important for use in electronic packaging and thermal insulation because it is necessary to reduce thermal stress and possible failure between two surfaces [8]. Meanwhile, the CTE has also been studied extensively in the aerospace shuttle particularly in the fuel tank to reduce the possibility of failure due to thermal stress [8]. An extensive study was also conducted on the characteristics of CTE of PU foam used as insulation for pipes and cooling gas cooler vehicles [9]. Meanwhile the report on other fillers such as glass microballoon did not include many findings on CTE in the literature review. In the recent study, CTE is decreased for three different types of glass microballoon [8]. Another study [10] also showed that CTE is lower than neat epoxy resins for different glass microballoon weight percentage $(0-2 \%$ by weight). It is also revealed that the reduction of CTE was reported for different volume fractions of glass microballoon mixed with epoxy resin in syntactic foam [11]. Therefore, these findings were not reported clearly about CTE relationship with the physical characteristics of glass microballoon especially porosity and voids are likely to have the same results with ceramic microballoon. In this study, the gap will be investigated to understand more deeply the effect of CTE of the glass microballoon. In order to improve the understanding of this relationship, several models have been introduced for the purposes of this study. Some report also showed Kerner and Turner model is suitable to be used for comparison with the experimental results of CTE [8]. It is also revealed that some models can estimate a CTE of the particulate composites. While another report also mentioned that several shape memory polymer (SMP) composites exhibited their CTE are comparable with theoretical model [12]. Turner as the founder of this model also assumes that the filler is considered as an isotropic material and thus CTE will not depend on the physical properties of the filler itself [13]. The report also found the changes in the dimensions of the constituent material having the same bulk specimens when associated with temperature, while Kerner with other co-founder of the polymer composite model estimated the CTE considering for shear and isostatic stress occurred in particulate phase composites [14]. Generally, both models use the thermosetting polymer composite matrix resin where CTE is closed to the experimental results within the scope of the wall thickness parameter. Thus, the theoretical and experimental approaches are used in this study to link the CTE with different weight percentages of glass microballoon (2-10\% by weight) in syntactic foam. All physical parameters of glass microballoon will be taken into account, such as syntactic foam density, wall thickness, radius ratio, porosity and voids content towards developing the use of lightweight materials for the application of thermal stability.

\section{METHODS AND MATERIALS}

\section{Investigation on Thermogravimetric analysis (TGA)}

TGA testing was carried out using NETZSCH TG 209F1 Libra equipment. The weight of the specimens were between $4 \mathrm{mg}$ to $8 \mathrm{mg}$, and different weight percentage of glass microballoon, were used for the analysis. The specimens were heated from $30^{\circ} \mathrm{C}$ to $800^{\circ} \mathrm{C}$ at a rate of $10^{\circ} \mathrm{C} / \mathrm{min}$. A differential thermogravimetric analysis (DTGA) curve was achieved 
from the TGA analysis. The heating conditions were maintained constant along the experiment.

\section{Investigation on Thermomechanical analysis (TMA)}

The linear dimension at different temperatures for the thermal expansion characteristics of the prepared specimen were evaluated by a thermomechanical analyser (TMA) using TA Instrument (Model TGA Q500), as shown in Figure 1. An expansion type probe was used to measure the temperature-dependent dimensional changes. A preload loading of $0.02 \mathrm{~N}$ was applied in all tests. A minimum of 3 coupons were prepared for each compositions. The samples were cut into pieces with dimensions L: $3 \mathrm{~mm} \times \mathrm{W}: 3 \mathrm{~mm} \times \mathrm{t}: 2 \mathrm{~mm}$. The external gas air input was used for cooling the TA unit system after finishing the testing. The heating rate in each run was kept at $3^{\circ} \mathrm{C} / \mathrm{min}$ and the temperature range was changed from ambient to $80^{\circ} \mathrm{C}$. Time, temperature and change in specimen height were recorded during the test. The slope of tangent, also called coefficient of thermal expansion (CTE), between Dimension change-temperature plot was determined and predicted as shows in Equation $(1)[8,9]$.

$$
\alpha=\left(\frac{1}{l}\right)\left(\frac{\Delta l}{\Delta T}\right)
$$

where $l$ initial length of specimen, $\frac{\Delta l}{\Delta T}$ slope of the graph.

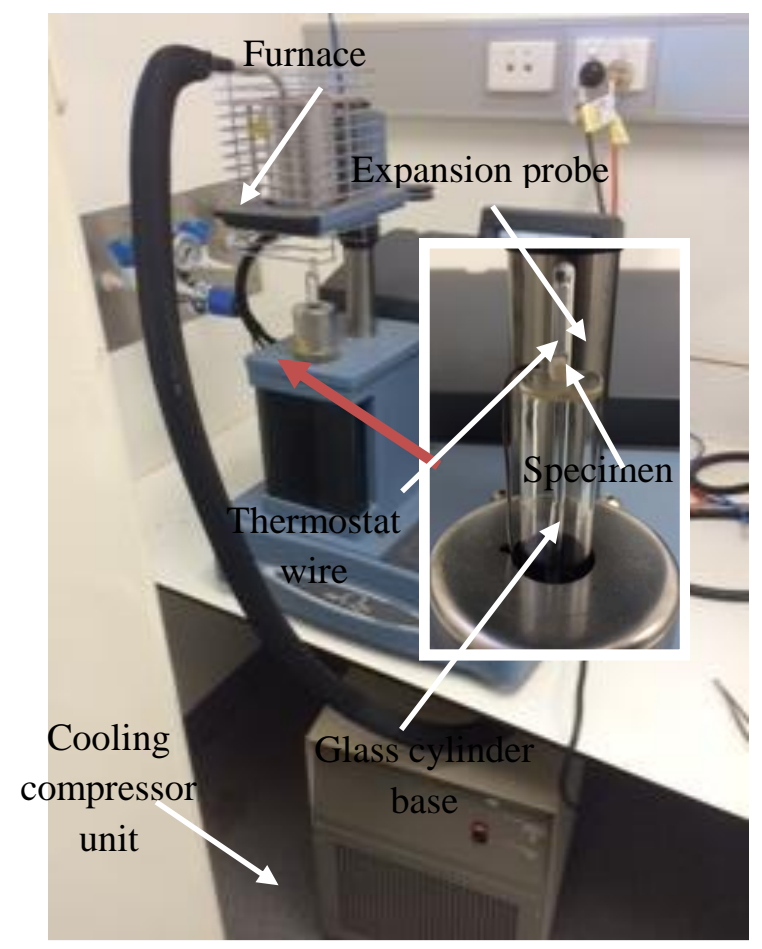

Figure 1: Overview of the thermomechanical analyser (TMA) machine 


\section{ANALYTICAL CALCULATION}

The Coefficient of Thermal Expansion (CTE) model, $\alpha$

The rule of mixture (ROM) is commonly used to obtain upper bound of various properties of composites material. Shunmugasamy et al. [8] have duplicated the relationship equation between ROM and CTE, as shown in Equation (2) below:

$$
\alpha=\alpha_{m} \beta_{m}+\alpha_{g} \beta_{g}
$$

where $\alpha_{m} \alpha_{g}$ is CTE for matrix resin and glass microballoon, respectively. The mixture of specimens in this study was weight percentage (wt. $\%$ ), therefore $\beta_{m}, \beta_{g}$ used wt.\% of matrix resin and wt.\% glass microballoon, instead of using volume fraction [8].

Kerner's and Tuner's models have been modified from previous reports by Shunmugasamy et al. [8] to include the physical parameters of glass microballoon, such as wall thickness and radius ratio, but excluding the porosity and voids. Therefore, in this study additional parameters have been included, starting with the derivation from Turner's model, as shown in Equation (3) below:

$$
\begin{gathered}
\alpha=\frac{\alpha_{m} \beta_{m} K_{m}+\alpha_{g} \beta_{g} K_{g}}{K_{m} \beta_{m}+\beta_{g} K_{g}} \\
\mathrm{~K}=\frac{E}{3(1-2 v)}
\end{gathered}
$$

Where $\mathrm{K}$ is a bulk moduli composite, considering $K_{\mathrm{m}}, K_{g}$, modulus of elasticity for matrix resin and glass microballoon, while E is Young's modulus and $v$ is Poisson's ratio of glass microballoon, respectively. An effective modulus of elasticity of glass microballoon can be assumed if the glass microballoon sphere has the same properties as the hollow glass microballoon, which is modified with porosities and voids content in syntactic foam, as shown in Equation (5) [15] and [16] below:

$$
\mathrm{E}_{\text {eff }}=\frac{\mathrm{E}_{g}(1-2 v)\left(1-\phi_{g}^{3}\right)\left(1-\phi_{m}\right)\left(1-\phi_{v}\right)}{(1-2 v)+\left(\frac{1+v}{2}\right) \phi_{g}^{3}+\left(\frac{1+v}{2}\right) \phi_{m}+\left(\frac{1+v}{2}\right) \phi_{v}}
$$

where $\phi_{g}, \phi_{m}$, and $\phi_{v}$ are percentages of cavity porosity, matrix porosity and voids content, respectively. In order to have a mutual understanding about the existing model, the standard specification has been used. Proposed value for modulus of elasticity glass microballoon $E_{g}$ can be used at $60 \mathrm{GPa}$ [17]. The final modified Turner model can be written up and divided by three equations as below in Equations (6), (7) and (8):

$$
\text { Cavity porosity, } \alpha_{\phi_{g}}=\frac{\alpha_{m} \beta_{m} E_{m}\left[\left(1-2 v_{g}\right)\left(\frac{1+v_{g}}{2}\right) \phi_{g}^{3}\right]+\alpha_{g} \beta_{g} E_{g}\left(1-2 \phi_{g}^{3}\right)\left(1-2 v_{m}\right)}{\beta_{m} E_{m}\left[\left(1-2 v_{g}\right)\left(\frac{1+v_{g}}{2}\right) \phi_{g}^{3}\right]+\beta_{g} E_{g}\left(1-2 \phi_{g}^{3}\right)\left(1-2 v_{m}\right)}
$$


Matrix porosity, $\alpha_{\phi_{m}}=\frac{\alpha_{m} \beta_{m} E_{m}\left[\left(1-2 v_{g}\right)\left(\frac{1+v_{g}}{2}\right) \phi_{m}^{3}\right]+\alpha_{g} \beta_{g} E_{g}\left(1-2 \phi_{m}^{3}\right)\left(1-2 v_{m}\right)}{\beta_{m} E_{m}\left[\left(1-2 v_{g}\right)\left(\frac{1+v_{g}}{2}\right) \phi_{m}^{3}\right]+\beta_{g} E_{g}\left(1-2 \phi_{m}^{3}\right)\left(1-2 v_{m}\right)}$

$$
\text { Voids, } \alpha_{\phi_{v}}=\frac{\alpha_{m} \beta_{m} E_{m}\left[\left(1-2 v_{g}\right)\left(\frac{1+v_{g}}{2}\right) \phi_{v}^{3}\right]+\alpha_{g} \beta_{g} E_{g}\left(1-2 \phi_{v}^{3}\right)\left(1-2 v_{m}\right)}{\beta_{m} E_{m}\left[\left(1-2 v_{g}\right)\left(\frac{1+v_{g}}{2}\right) \phi_{v}^{3}\right]+\beta_{g} E_{g}\left(1-2 \phi_{v}^{3}\right)\left(1-2 v_{m}\right)}
$$

where $v_{g}$ is Poisson's ratio of glass microballoon, which can be used as 0.21 , while the modulus of elasticity, $\mathrm{E}_{\mathrm{m}}$ vinyl ester matrix resin, is used as $22.82 \mathrm{GPa}$ [4] and $v_{m}$ is Poisson's ratio as 0.35 [18]. In this prediction, the void content can be ignored from the modelling in Turner's model because air/gas trap in syntactic foam is not required for higher percentages $(<5 \%)$ in terms of its contribution to the evaluation. Thus, the CTE values investigation only focused on radius ratio's $(\eta)$, cavity porosity $\left(\phi_{g}\right)$ and matrix porosity $\left(\phi_{m}\right)$.

\section{Theoretical Study on Kinetic Energy for Polymer Degradation}

The kinetic energy for polymer degradation commonly uses the Equation (9) introduced by Flynn [19].

$$
\frac{\mathrm{d} \alpha}{\mathrm{dt}}=\mathrm{k}(\mathrm{T}) \mathrm{f}(\alpha)
$$

where $\alpha$ represents conversion factor $(\alpha=0-1)$, t is the time, $\mathrm{k}(\mathrm{T})$ is temperature rate constant and $f(\alpha)$ is the reaction model, which describes the dependence of the reaction rate on the extent of the reaction. The temperature dependence of $k(T)$ could be represented by the Arrhenius Equation (10).

$$
\frac{\mathrm{d} \alpha}{\mathrm{dt}}=\mathrm{Ae}^{\frac{-E_{a}}{R T}} \mathrm{f}(\alpha)
$$

where $\mathrm{E}_{\mathrm{a}}$ is activation energy of the process. $\mathrm{A}$ is the pre-exponential factor, $\mathrm{R}$ is the universal gas constant and $f(\alpha)$ depends on the decomposition mechanism. The simplest and most frequently used model for $f(\alpha)$ is shown in Equation (11),

$$
f(\alpha)=(1-\alpha)^{n}
$$

where $\mathrm{n}$ is order of reaction, while the rate of conversion, $\mathrm{d} \alpha / \mathrm{dt}$ can be written as,

$$
\frac{\mathrm{d} \alpha}{\mathrm{dt}}=\mathrm{k}=\mathrm{k}(\mathrm{T}) \mathrm{f}(\alpha)
$$

The combination of Equation (10 - 12) gives the following relationship, as shown in Equation (13),

$$
\frac{\mathrm{d} \alpha}{\mathrm{dt}}=\mathrm{k}=(1-\alpha)^{\mathrm{n}} \mathrm{Ae}^{\frac{-E_{a}}{R T}}
$$


and the first order reaction ( $\mathrm{n}=1)$ and Equation (13) can be expressed as,

$$
\frac{\mathrm{d} \alpha}{\mathrm{dt}}=\mathrm{k}=\mathrm{Ae}^{\frac{-E_{a}}{R T}}
$$

Therefore, the Arrhenius equation can also be shown as Equation (14) above. In a chemical kinetics reaction, the rate constant quantifies the speed of a chemical reaction. It is also quantified by a frequency factor or a factor is the pre-exponential constant in the Arrhenius equation, which can be expressed as in Equation (15),

$$
\ln (\mathrm{k})=\frac{-\mathrm{E}_{\mathrm{a}}}{\mathrm{RT}}+\ln (\mathrm{A})
$$

Then, a reaction obeys the Arrhenius equation as a plot of $\ln (\mathrm{k})$ versus $\mathrm{T}^{-1}$ will give a straight line, or slope and an intercept can be used to determine $\mathrm{E}_{\mathrm{a}}$ and $\mathrm{A}$. The final activation energy can be defined as (-R) multiplied by the slope of the graph.

$$
\mathrm{E}_{\mathrm{a}}=-\mathrm{R}\left(\frac{\Delta \ln (\mathrm{k})}{\Delta \ln \left(\frac{1}{\mathrm{~T}}\right)}\right)
$$

Studying kinetic energy, particularly activation energy, can be described in the form of many methods. There are several methods that can determine kinetic energy [20]. The well-known method called the Broido Method is useful to determine the kinetic parameters, which can be derived from mass loss versus temperature [21]. Equation (17) shows the derivation of the Broido Method [22],

$$
\ln \left(\ln \frac{1}{\mathrm{Y}}\right)=-\frac{\mathrm{E}_{a}}{\mathrm{R}}\left(\frac{1}{\mathrm{~T}}\right)+\ln \left(\frac{\mathrm{R}}{\mathrm{E}_{a}} \cdot \frac{\mathrm{Z}}{\mathrm{R}_{\mathrm{H}}} \cdot \mathrm{T}_{\mathrm{m}}^{2}\right)
$$

where $(1 / \mathrm{Y})$ is the fraction of the number of initial molecules not yet decomposed, $\mathrm{R}$ is the universal gas constant $\left(8.31451 \mathrm{JK}^{-1} \mathrm{~mol}^{-1}\right), \mathrm{T}_{\mathrm{m}}$ is the temperature of the maximum decomposition rate unit Kelvin $(\mathrm{K}), \mathrm{R}_{\mathrm{H}}$ is the heating rate $\left(\mathrm{Kmin}^{-1}\right)$ and $\mathrm{Z}$ is frequency factor $\mathrm{s}^{-1}$.

\section{RESULTS AND DISCUSSION}

\section{Coefficient of Thermal Expansion (CTE), $\alpha$ physical properties}

From the experimental results, CTEs were analysed and compared to understand the effect of the physical parameters of syntactic foam on CTE. The CTE result for all specimens, including pure vinyl ester, is shown in Figure 2. It shows that the CTE of glass microballoon syntactic foam decreased when the glass microballoon in syntactic foam was increased. This graph reveals a 30-70\% decrease in the CTE of syntactic foams compared to the neat resin result. The lowest CTE value was observed for $10 \mathrm{wt} . \%$ glass microballoon, which contained the lowest average wall thickness, as shown in Table 4 . The reduction of CTE related to the physical properties of glass microballoons, such as wall thickness, radius ratio, porosities and voids, which were interesting to discover for a more concrete understanding of how to obtain the quantitative parameters in this study. The percentage reduction of the CTE can be determined with a different (ratio) starting from pure vinyl ester and a specimen of $2 \mathrm{wt} . \%$, which is also shown in Table 1. Incorporation of filling with glass microballoon resulted in 
up to a $63 \%$ reduction and it kept decreasing to $53 \%$ for a temperature change from $30^{\circ} \mathrm{C}$ to $70^{\circ} \mathrm{C}$.

Table 1: CTE syntactic foam at different temperature

\begin{tabular}{ccccccc}
\hline & $\mathrm{CTE}$ & $\mathrm{T}: 30^{\circ} \mathrm{C}$ & $\mathrm{CTE}$ & $\mathrm{T}: 50^{\circ} \mathrm{C}$ & $\mathrm{CTE}$ & $\mathrm{T}: 70^{\circ} \mathrm{C}$ \\
\hline Specimens & $\alpha\left(\mu \mathrm{m}^{\circ} \mathrm{C}^{-1}\right)$ & $\Delta(\%)$ & $\alpha\left(\mu \mathrm{m}^{\circ} \mathrm{C}^{-1}\right)$ & $\Delta(\%)$ & $\alpha\left(\mu \mathrm{m}^{\circ} \mathrm{C}^{-1}\right)$ & $\Delta(\%)$ \\
Pure VE & 100.18 & - & - & - & - & - \\
2wt.\% & 63.70 & -36.41 & 68.59 & -31.53 & 69.50 & -30.62 \\
4wt.\% & 59.15 & -40.95 & 58.99 & -41.12 & 45.80 & -54.27 \\
6wt.\% & 41.58 & -58.49 & 56.88 & -43.22 & 32.80 & -67.25 \\
8wt.\% & 38.89 & -61.18 & 45.38 & -54.69 & 57.06 & -43.04 \\
10wt.\% & 36.71 & -63.35 & 44.61 & -55.46 & 46.77 & -53.31 \\
\hline
\end{tabular}

The CTE values between $4 \mathrm{wt} . \%$ and $6 \mathrm{wt} . \%$, and between $8 \mathrm{wt} . \%$ and $10 \mathrm{wt} . \%$ did not have much difference between them, whereas they were almost $5 \%$ and $1 \%$ if compared to each other, respectively. This gap could be contributed to the porosity and voids content occurring in the syntactic foam with a debris of glass microballoons. The thermal flow through these kinds of mechanism will affect the CTE value in the syntactic foams and can be seen in the SEM photo in Figure 3. The specimen with 2wt.\% had the highest CTE value, which also corresponded to the lower glass microballoon. This trend was also detected by Shunmugasamy et al. [8] who also noted that the CTE value decreased when glass microballoon was added (with a 30-60\% volume fraction) into the vinyl ester matrix resin.

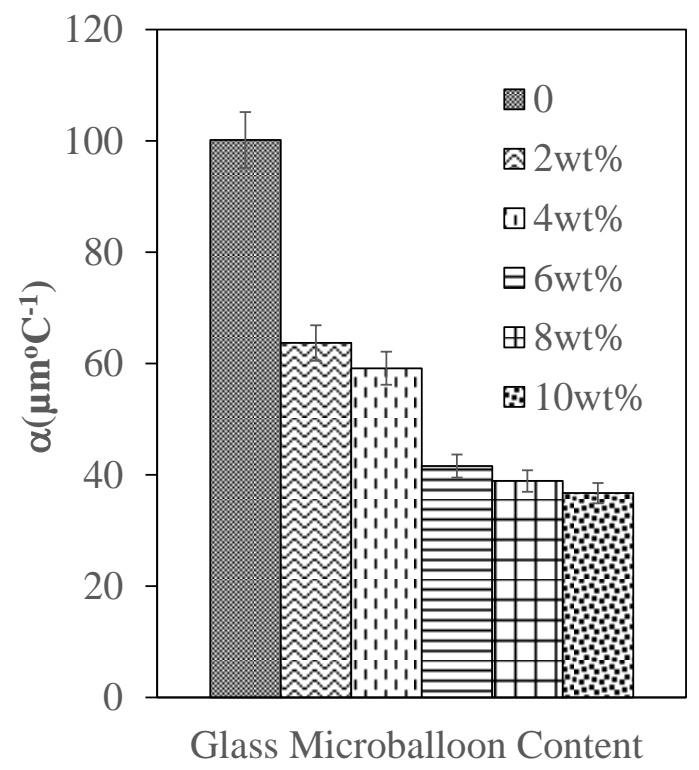

Figure 2: Experimental CTE measured values for neat resin and syntactic foam 


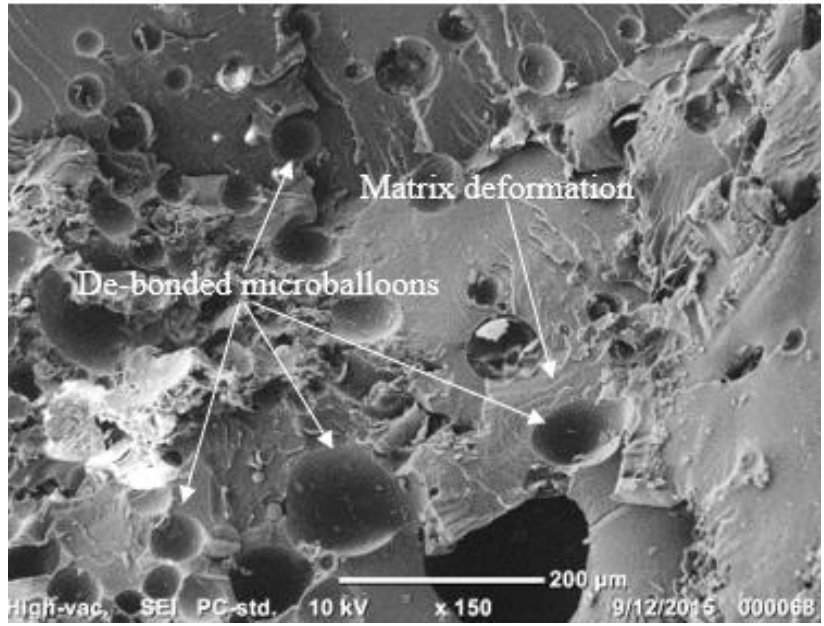

Figure 3: SEM images of the fracture surface of the specimens after being immersed in water

\section{Comparative study on CTE using Turner's model}

The CTE in the experimental result was analysed and plotted to be normalised in the CTE vinyl ester resin as shown in Figure 4. The CTE function was considered at different weight percentages of (wt.\%) glass microballoons at temperatures of $30^{\circ} \mathrm{C}, 50^{\circ} \mathrm{C}$ and $70^{\circ} \mathrm{C}$. Generally, the normalised CTE steeply decreased when glass microballoon was added from lower to higher temperature conditions. According to the graph, normalised CTE at a temperature of $70^{\circ} \mathrm{C}$ shows to be more stable when compared to other temperatures, particularly in combination with more than $4 \mathrm{wt} . \%$ of glass microballoon. It shows that a lower thermal heat resistance application was also useful and not only for weight saving composite material, with varied wall thickness as reported by Shunmugasamy et al. [8]. Starting from $2 \mathrm{wt} . \%$, the behaviour showed a more polymerised condition with $20 \%$, which is different from pure resin CTE. The variation between three different temperatures did also have almost no gap between 1 to $5 \%$, when close to each other. Normalised CTE rapidly changed at between $6-8 \mathrm{wt} . \%$ but until $10 \mathrm{wt} . \%$ it was suitable to be used for lower heat transfer applications at $30^{\circ} \mathrm{C}$.

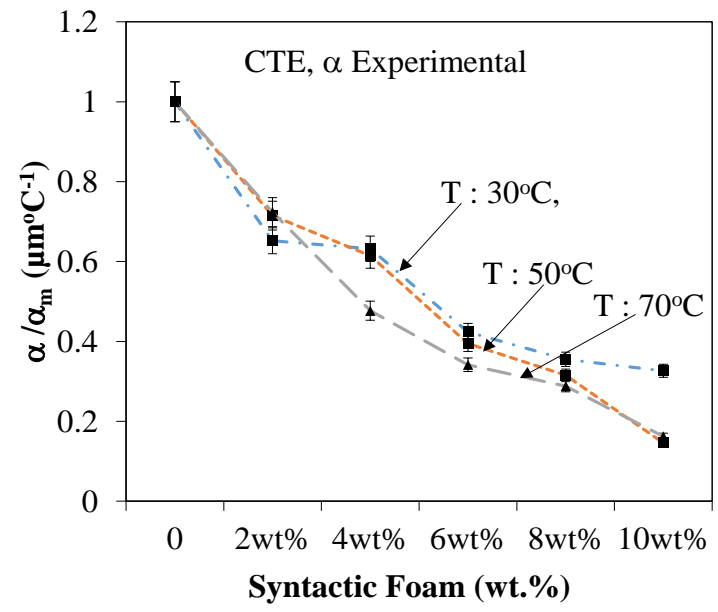

Figure 4: Normalised CTE function of wt.\% glass microballoon. 
The dimension changed at various temperatures, which shows that a temperature of $30^{\circ} \mathrm{C}$, obtained from a specimen with $2 \mathrm{wt} . \%$, had a lower expansion rate, with the highest slope of dimension change-temperature plot at $0.2006 \mu \mathrm{m} /{ }^{\circ} \mathrm{C}$. This characteristic behaviour made polymeric resin the dominantly crystallised influence in syntactic foam. Furthermore, the specimen of $4 \mathrm{wt} . \%$, between temperatures $30^{\circ} \mathrm{C}$ and $50^{\circ} \mathrm{C}$, exhibited a similar CTE value of $\alpha=58 \mu \mathrm{m}^{\circ} \mathrm{C}^{-1}$. The modified Turner's model was used to predict the CTE values function with different glass microballoon (wt.\%), as shown in Figure 4. The CTE value also varied within a different parametric investigation, whereby radius ratio $(\eta)$, cavity porosity $\left(\phi_{\mathrm{g}}\right)$, and matrix porosity $\left(\phi_{\mathrm{m}}\right)$ were estimated at three different temperatures: $30^{\circ} \mathrm{C}, 50^{\circ} \mathrm{C}$ and $70^{\circ} \mathrm{C}$. Generally, the CTE value decreased when the glass microballoon content was increased at different temperatures, thus following the experimental values. Similar work has also revealed that a parametric study on the wall thickness of glass microballoons decreased their CTE values when the filler content was increased in syntactic foam [8]. From the graph, it can be predicted that Turner's model showing CTE values was varied in terms of radius ratio, $\eta$ and syntactic foam for different wt.\% of glass microballoons. The CTE decreased from 70 - $37 \mu \mathrm{m}^{\circ} \mathrm{C}^{-1}$, which led to a milder effect on the radius of the glass microballoon. Turner's model CTE trend value closely matched the experimental results, particularly specimens 4 , 8 and $10 \mathrm{wt} . \%$ for a temperature at $30^{\circ} \mathrm{C}$. At temperatures of $50^{\circ} \mathrm{C}$ and $70^{\circ} \mathrm{C}$, Turner's CTE model values were nearest to the experimental results at $4 \mathrm{wt} . \%$ glass microballoons. In conjunction with additional glass microballoons, the estimation of CTE in Turner's model will have a reduction from $66 \%$ to $36 \%$ with varied temperature conditions, as shown in Table 2.

Turner's prediction model, when related to porosity in this study, revealed that the CTE trend for both cavity porosity and matrix porosity were close to each other. This is also evidence that both porosities were present in all specimens and that it increased their percentage in Table 1 when many fractured glass microballoons in the syntactic foam occurred. At a temperature of $30^{\circ} \mathrm{C}$, Turner's model predicted a lower CTE when compared to the experimental result. Within this behaviour, $\alpha$ was decreased from $28 \mu \mathrm{m}^{\circ} \mathrm{C}^{-1}$ to 19 $\mu \mathrm{m}^{\circ} \mathrm{C}^{-1}$ but still below the $\alpha$ experimental with $38 \mu \mathrm{m}^{\circ} \mathrm{C}^{-1}$. Also in this model, many CTE values were much higher than the experimental $\mathrm{CTE}$ value with elevated temperature conditions especially at $50-70^{\circ} \mathrm{C}$. This model could predict that the CTE value was close to the experiment for the composition of glass microballoons of between $2 \mathrm{wt} . \%$ and $4 \mathrm{wt} . \%$, while a higher composition of glass microballoon thus contributed more porosity. As a result, a gap occurred between the experimental CTE result and Turner's porosities model especially at a temperature of $70^{\circ} \mathrm{C}$ with large gap CTE, $\alpha: 48-57 \mu \mathrm{m}^{\circ} \mathrm{C}^{-1}$. The reduction of the CTE could be calculated by using this model from $78 \%$ to $44 \%$ and $80 \%$ to $45 \%$ for cavity porosity and matrix porosity, respectively as shown in Table 2 . Therefore, this model predicted that the CTE was higher in porosity at a high temperature even though there was a decreasing trend towards being inclusive in terms of glass microballoon content.

In this study, the average diameter glass microballoon, with a range of $72-75 \mu \mathrm{m}$ was used with the average $r_{o}$ and $r_{i}$ that could be estimated at a range of between 36-38 $\mu \mathrm{m}$ size, respectively. Hence, the wall thickness of this microballoon could be calculated by using the equation introduced by [23]. The thermal stability of this syntactic foam could be varied in terms of wall thickness, due to a different radius of glass microballoon. Similar results have also been detected in previous studies where the thin wall thickness $(1-\eta)<0.4$, decreased 
the CTE sharply, which was similar in this report. This could be happening when the porosities regime was dominantly in the syntactic foam, which was contributed to an increase in the CTE value. Therefore, porosity also contributed to a change in phase- transformation, which occurred internally in the syntactic foam. It can be seen in Figure 5 that the dimensional change occurred nonlinearly up to a glass transition temperature, $\mathrm{T}_{\mathrm{g}}$ of syntactic foam. Beyond this temperature, the behaviour of syntactic foam totally changed in terms of the dimensional variation and it changed to a fairly linear graph. Saha et al. [24] also found similar results for epoxy resin composite. The potential changes in phase with the dimensional stability of the various types of glass microballoon when mixed with an epoxy resin [25].
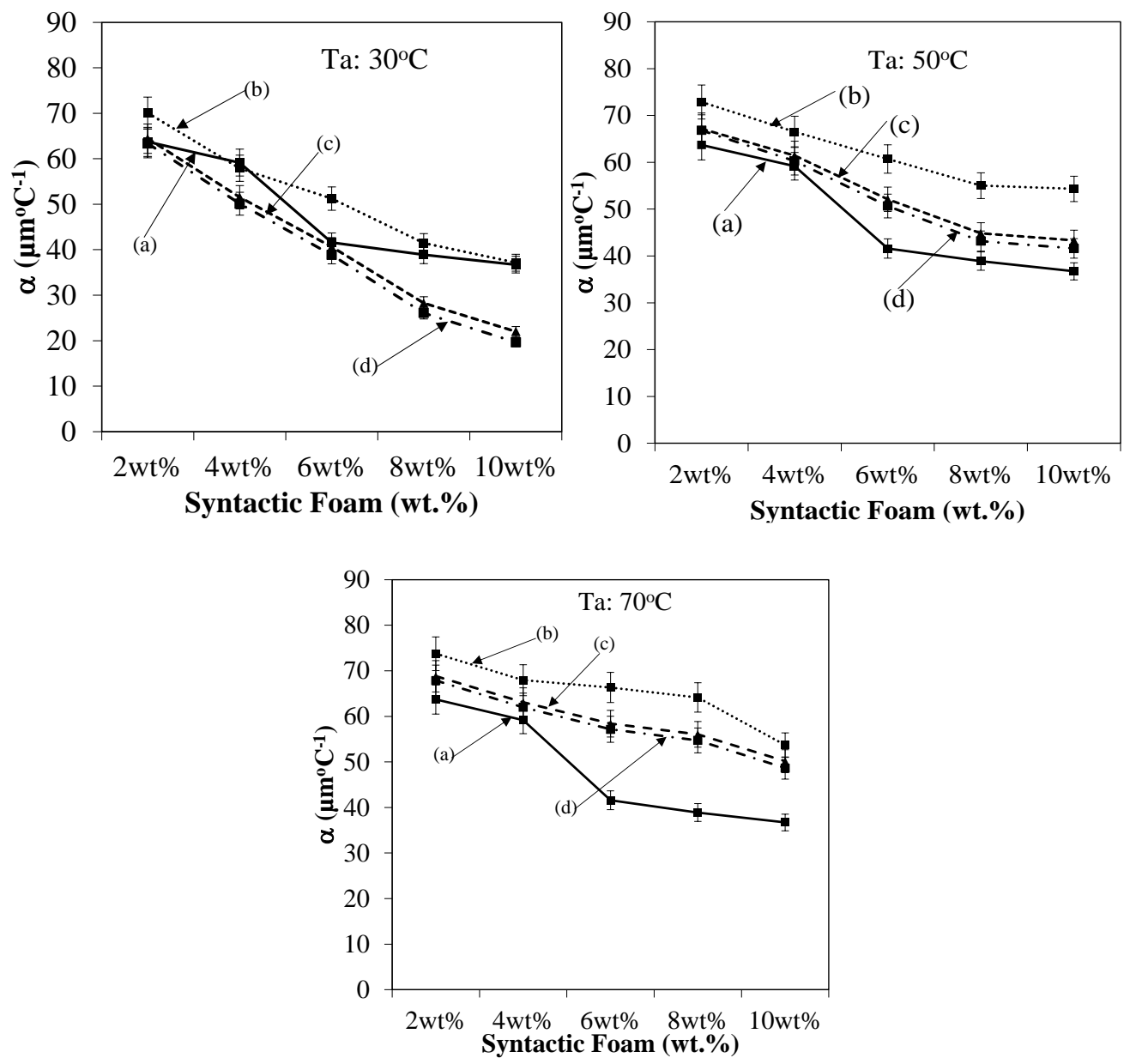

Figure 5: Typical comparison of CTE values using Turner's model (a) Experimental (b) Radius ratio ( $\eta)$, (c) Cavity porosity $\left(\phi_{\mathrm{g}}\right)$, (d) Matrix porosity $\left(\phi_{\mathrm{m}}\right)$ 
Table 2: Difference $(\Delta)$ of $\alpha$ CTE Tuner's model at temperature $30^{\circ} \mathrm{C}, 50^{\circ} \mathrm{C}$ and $70^{\circ} \mathrm{C}$.

\begin{tabular}{|c|c|c|c|}
\hline Specimen & $\begin{array}{l}\text { Tuner's Model } \\
\text { Radius ratio, } \eta\end{array}$ & $\begin{array}{l}\text { Tuner's Model } \\
\text { Cavity Porosity, } \\
\phi_{\mathrm{g}} \\
\end{array}$ & $\begin{array}{lr}\text { Tuner's } & \text { Model } \\
\text { Matrix } & \text { Porosity, } \\
\phi \mathrm{m} & \\
\end{array}$ \\
\hline Different at $30^{\circ} \mathrm{C}$ & $\Delta(\%)$ & $\Delta(\%)$ & $\Delta(\%)$ \\
\hline $2 \mathrm{wt} \%$ & -30.08 & -35.70 & -36.77 \\
\hline $4 \mathrm{wt} \%$ & -42.21 & -48.55 & -49.99 \\
\hline $6 \mathrm{wt} \%$ & -48.84 & -59.45 & -61.24 \\
\hline $8 \mathrm{wt} \%$ & -58.63 & -71.79 & -73.97 \\
\hline $10 \mathrm{wt} \%$ & -62.93 & -78.02 & -80.38 \\
\hline Different at $50^{\circ} \mathrm{C}$ & $\Delta(\%)$ & $\Delta(\%)$ & $\Delta(\%)$ \\
\hline $2 \mathrm{wt} \%$ & -27.26 & -32.97 & -33.32 \\
\hline $4 \mathrm{wt} \%$ & -33.63 & -38.69 & -39.83 \\
\hline $6 \mathrm{wt} \%$ & -39.43 & -47.99 & -49.44 \\
\hline $8 \mathrm{wt} \%$ & -45.10 & -55.23 & -56.91 \\
\hline $10 \mathrm{wt} \%$ & -45.78 & -56.76 & -58.48 \\
\hline Different at $70^{\circ} \mathrm{C}$ & $\Delta(\%)$ & $\Delta(\%)$ & $\Delta(\%)$ \\
\hline $2 \mathrm{wt} \%$ & -26.39 & -31.32 & -32.26 \\
\hline $4 \mathrm{wt} \%$ & -32.19 & -37.03 & -38.12 \\
\hline $6 \mathrm{wt} \%$ & -33.79 & -41.70 & -42.95 \\
\hline $8 \mathrm{wt} \%$ & -35.97 & -44.04 & -45.38 \\
\hline $10 \mathrm{wt} \%$ & -46.42 & -49.93 & -51.44 \\
\hline
\end{tabular}

\section{CONCLUSIONS}

In this study, the linear dimension stability, also called coefficient of thermal expansion $\alpha$ (CTE), decreased when the glass microballoon content increased. An addition with glass microballoon resulted in up to a $63 \%$ reduction of CTE and it kept decreasing to $53 \%$ for a temperature change from $30^{\circ} \mathrm{C}$ to $70^{\circ} \mathrm{C}$. The modification of Turner's model was applied in this study for a comparison of CTE in three different temperatures $\left(30^{\circ} \mathrm{C}, 50^{\circ} \mathrm{C}\right.$ and $\left.70^{\circ} \mathrm{C}\right)$ for syntactic foams. The modification included parametric study involvement into the effect of radius ratio, porosity and void content in syntactic foams. Moreover, additional glass microballoons can also comparatively estimate CTE in Turner's model having a reduction from $66 \%$ to $36 \%$ with varied temperature conditions. The reduction of the CTE from this model could also be reduced from $78 \%$ to $44 \%$ and $80 \%$ to $45 \%$ for cavity porosity and matrix porosity in syntactic foams.

\section{ACKNOWLEDGEMENTS}

The authors would like to thank Majlis Amanah Rakyat (MARA), Malaysia and Universiti Kuala Lumpur Malaysian Institute of Marine Engineering Technology, Malaysia for providing scholarship to the first author on doing this work. 


\section{REFERENCES}

[1] Gupta N, Woldesenbet E, and Mensah P. Compression Properties of Syntactic Foams: Effect of Cenosphere Radius Ratio and Specimen Aspect Ratio. Composites: Part A. 2004; 35: 103-111.

[2] Gupta N and Nagorny R. Tensile properties of glass microballoon-epoxy resin syntactic foams. Journal of Applied Polymer Science. 2006; 102: 1254-1261.

[3] Porfiri M and Gupta N. Effect of volume fraction and wall thickness on the elastic properties of hollow particle filled composites. Composites B Engineering. 2009; 40: $166-173$.

[4] Gupta N, Ye N, and Porfiri M. Comparison of tensile and compressive characteristics of vinyl ester/glass microballoon syntactic foams. Composites Part B: Engineering. 2010; 41: 236-245.

[5] Gupta N and Shunmugasamy VC. High strain rate compressive response of syntactic foams: Trends in mechanical properties and failure mechanisms. Materials Science and Engineering A. 2011; 528: 7596-7605.

[6] Devi K, John B, and Ninan CNK. Effect of low-density filler on mechanical properties of syntactic foams of cyanate ester. Journal Applied Polymer Science. 2007.

[7] Salleh Z, Islam M, and Ku H. Study on Compressive Properties of Syntactic Foams for Marine Applications. Journal of Multifunctional Composite. 2014:21-27.

[8] Shunmugasamy VC, Pinisetty D, and Gupta N. Thermal expansion behavior of hollow glass particle/vinyl ester composites. Journal of Materials Science. 2012; 47: 5596-5604.

[9] Kim MK, Kwon KJ, and Han YK. Synthesis of Cardo Based Poly(arylene ether)s for Flexible Plastic Substrates and Their Properties. Bull. Korean Chem. Soc.2011; 32: 3311-3316.

[10] Park S, Jin F, and Lee C. Preparation and physical properties of hollow glass microspheres-reinforced epoxy matrix resins. Material Science Engineering A. 2005; 402: 335-340.

[11] Yung K, Zhu B, Yue T, and Xie C. Preparation and properties of hollow glass microsphere-filled epoxy-matrix composites. Composites Science and Technology. 2009; 69: 260-264.

[12] Shirasua K, Nakamuraa A, Yamamoto G, Ogasawara T, Shimamura Y, Inoue Y, and Hashida T. Potential use of CNTs for production of zero thermal expansioncoefficient composite materials: An experimental evaluation of axialthermal expansion coefficient of CNTs using a combination of thermalexpansion and uniaxial tensile tests. Composites Part A. 2017; 95: 152-160.

[13] Sharma NK, Misra RK and Sharma TP. Modeling of thermal expansion behavior of densely packed $\mathrm{Al} / \mathrm{SiC}$ composites. International Journal of Solids and Structures Volumes. 2016; 102-103: 77-88.

[14] Sharma NK, Misra RK, Sharma S. Thermal expansion behavior of Ni-Al2O3 composites with particulate and interpenetrating phase structures: an analysis using finite element method. 2014; 90: 130-136.

[15] Ellis SN, Romao CP and White MA. Near-Zero Thermal Expansion in Freeze-Cast Composite Materials. Ceramics 2019; 2: 112-125. 
[16] Soares AR, Ponton PI, Mancic L, d'Almeida JRM, Romao CP, White MA, Marinkovic BA. A12Mo3O12/polyethylene composites with reduced coefficient of thermal expansion. Journal Material. Science. 2014; 49: 7870-7882.

[17] Tagliavia G, Porfiri M, and Gupta N. Vinyl ester-glass hollow particle composites: dynamic mechanical properties at high inclusion volume fraction. Journal Composite Material. 2009; 43: 561-582.

[18] Poveda R, Gupta N, and Porfiri M. Material Letter. 2010; 64: 2360.

[19] JH Flynn. Encyclopedia of Polymer Science and Engineering. New York: Wiley, 1989.

[20] Das AM, Ali AA, and Hazarika MP. Thermal Degradation and Kinetic Study of Vinyl ester Monomer Grafted Silk Fibroin. International Journal of Engineering and Technical Research (IJETR). 2014; 2: 69-78.

[21] Gao Z, Tao F and Ren J. Unusually low thermal conductivity of atomically thin 2D tellurium. 2018; 10: 12997-13003.

[22] Gopalakrishnan S and Sujatha R. Comparative thermoanalytical studies of polyurethanes using Coats-Redfern, Broido and Horowitz-Metzger methods Der Chemica Sinica. 2011; 2: 103-117.

[23] Baskaran R, Sarojadevi M, and Vijayakumar CT. Utilization of Granite Powder as Filler for Vinyl ester Resin. Malaysian Polymer Journal. 2014;9.

[24] Saha MC, Nilufar S, Major M, and Jeelani S. Processing and Performance Evaluation of Hollow Microspheres Filled Epoxy Composites. Polymer Composites. 2008; 29: 293-301.

[25] Tien C, Gupta N, and Talalayev A. Thermoanalytical characterization of epoxy matrix-glass microballoon syntactic foams. Journal Material Science. 2009; 44: $1520-1527$. 